\title{
Outcomes and Quality of Life of Patients with a Digestive Stoma in Sub-Saharan Africa: Case of the Yaounde Central Hospital, Cameroon
}

\author{
Georges Bwelle Motto1,2, Guy Aristide Bang1, Joseph Cyrille Chopkeng Ngoumfe ${ }^{2 *}$, \\ Yannick Mahamat Ekani Boukar ${ }^{3}$, Raissa Larissa Kom de Sendjong2, \\ Bernadette Ngo Nonga ${ }^{1}$, Maurice Aurélien Sosso ${ }^{1}$
}

\author{
${ }^{1}$ Department of Surgery and Specialties, Faculty of Medicine and Biomedical Sciences, The University of Yaoundé I, \\ Yaoundé, Cameroon \\ ${ }^{2}$ Department of Visceral and Digestive Surgery, Yaoundé Central Hospital, Yaoundé, Cameroon \\ ${ }^{3}$ Department of Surgery, University of Buea, Buea, Cameroon \\ Email: gbwelle@gmail.com, guyaristidebang@yahoo.fr, *chopkeng.c@gmail.com, boukaryoussouf@gmail.com, \\ komraissa95@gmail.com,ngonongab@yahoo.com, sossomaurice@yahoo.fr
}

How to cite this paper: Bwelle Motto, G. Bang, G.A., Chopkeng Ngoumfe, J.C., Ekani Boukar, Y.M., Kom de Sendjong, R.L., Ngo Nonga, B. and Sosso, M.A. (2021) Outcomes and Quality of Life of Patients with a Digestive Stoma in Sub-Saharan Africa: Case of the Yaounde Central Hospital, Cameroon. Surgical Science, 12, 381-389. https://doi.org/10.4236/ss.2021.1211040

Received: October 5, 2021

Accepted: November 26, 2021

Published: November 29, 2021

Copyright $\odot 2021$ by author(s) and Scientific Research Publishing Inc. This work is licensed under the Creative Commons Attribution International License (CC BY 4.0).

http://creativecommons.org/licenses/by/4.0/

\begin{abstract}
Introduction: The installation of a digestive stoma involves changes affecting all aspects of the patients' lives. The objective of this study was to determine the impact of a digestive stoma on the quality of life of patients operated on at the Yaounde Central Hospital (YCH). Patients and Methodology: We conducted a prospective descriptive study over a period of 12 months from June 2018 to May 2019 in all patients with a digestive stoma for at least 3 months operated on at the YCH. The follow-up was done within 12 months. Quality of life was assessed using the stoma QOL (quality of life) and self-image using the BIS (Body Image Scale). Results: We collected a total of 34 patients, of whom 22 were male, giving an $\mathrm{M} / \mathrm{F}$ sex ratio of 1.8 . The average age of the patients was 42.8 years. The indications were tumoral in $44.11 \%$ of cases $(n=15)$ and non-tumoral in $55.88 \%$ of cases $(\mathrm{n}=19)$. The colon was the most frequently ablated organ $(n=26)$ with $76.5 \%$ of colostomies. The complication rate was $67.6 \%$. Stomal oedema was the most common early complication with $38.2 \%$ of cases. All patients used colostomy bags. The average time to return to sexual activity was 8 months for men and 9 months for women. $85.3 \%$ of the patients had an average impairment of quality of life according to the Stoma Quality of Life Scale. According to the Body Image Scale, $73.5 \%$ of the patients had a moderate dissatisfaction with their self-image. Conclusion: The realization of a digestive stoma imposes a long-term follow-up especially on the psychological level in order to allow the empowerment of the patients who all have a modification of their quality of life and their self-image.
\end{abstract}




\section{Keywords}

Stoma, Quality of Life, Self-Image Cameroon

\section{Introduction}

A digestive stoma is the connection of a digestive viscera to the skin outside its natural location [1]. It can involve different segments of the digestive tract and can be used for exoneration or feeding. It is a common practice throughout the world with a large patient population of approximately 1.5 million in the USA, 80,000 in France and 45,000 in the UK [2]. In China, 38\% of colostomies and $29 \%$ of ileostomies are performed annually [3] [4]. In Africa, it represents $7.4 \%$ of all surgical procedures in Mali [5]. Regardless of the country or continent, colostomy seems to be the most commonly performed diversion [2] [3].

The indications for this surgical practice are diverse and varied, and may be tumour-related or not. Colorectal cancer is the most prevalent indication in the West, as in Africa [3] [4] [5].

The use of a digestive stoma involves the loss of organ function and control, and implies changes affecting all aspects of the patient's life [4]. These changes can be surgical, medical and even psychological in the long term with an impact of the stoma on body image, self-esteem and relationships.

Electrolyte disorders have been found in China to be one of the most frequent early complications, while in Denmark and France trophic disorders prevail [3] [4] [6]. In Africa, undernutrition is added to these skin complications [5] [7].

A study carried out in Cameroon found a rate of surgical complications of $19 \%$ [8]. The psychological impact of the stoma is not insignificant, as it requires adaptation to this form of disability and the repercussions on quality of life can go as far as social isolation [4].

In most studies, the quality of life of patients with a digestive stoma remains disturbed [9] [10] [11] [12]. If in developed countries ostomate patients have difficulties of social reintegration after ostomy, it seemed appropriate to us to determine the psychological and social impact of ostomy on patients derived from the digestive tract in our environment with diverse cultures and multiple taboos.

\section{Patients and Methods}

We conducted a prospective descriptive study over a period of 12 months from June 2018 to May 2019 at the YCH. The choice of this hospital is justified by the fact that it has the largest proctological surgery activity in the city of Yaoundé.

All adult patients over 15 years of age with a digestive stoma for at least 3 months were included in the study.

The sampling was consecutive.

Prospectively, we collected the files of all patients aged at least 15 years who 
had a digestive stoma from June 2018 to May 2019 (i.e., 12 months). These patients were then reviewed in consultation at 3 months, 6 months and 12 months after surgery to assess their quality of life.

The variables studied were socio-demographic data, clinical data, and lifestyle with the stoma. Follow-up was for 12 months.

Quality of life was assessed using the stoma QOL (quality of life) [4]. It consists of 20 questions assessed on a 4-point scale. The points obtained for each of the 20 questions are added together to obtain an overall score. This summary raw score per patient is in the range of 20 - 80. The higher the Stoma-QOL score, the better the Quality of Life.

Self-image was assessed using the BIS (Body Image Scale) [4]. It measures the impact of treatment and illness on body image through 10 questions with 4 choices of answers. The higher the score, the more satisfactory the individual's body image is.

An interview was conducted by one of the investigators to evaluate the quality of live according to Stoma QOL and BIS. If necessary, some items were explained to the participants in local language

Data were recorded using CS Pro version 7 software and analysed using IBM_ SPSS (Statistical Package of Social Sciences) version 23.0. Qualitative data were expressed as headcount and percentage; illustrated in tables and figures. Chisquare and Fischer tests were used to test for association between categorical values; while the student's $t$ test was used to compare means.

Ethical clearance was obtained from the Research and Ethics Committee of the Faculty of Medicine and Pharmaceutical Sciences, University of Douala. Study authorization was obtained from the administrative services of the $\mathrm{YCH}$.

\section{Results}

Among the 293 surgeries performed during the study period in the visceral surgery department, we recorded 34 cases of digestive stomas, with a prevalence of $11.60 \%$. Of these, 22 were men, giving a sex ratio $\mathrm{M} / \mathrm{F}$ of 1.8 . The average age of the patients was 42.8 years with extremes ranging from 16 to 83 years. The most represented age group was 36 - 45 years with $35.4 \%$. Table 1 shows the socio-demographic characteristics of the patients.

The indications were tumour in $44.11 \%$ of cases $(n=15)$ and non-tumour in $55.89 \%$ of cases $(\mathrm{n}=19)$. The colon was the most frequently ablated organ $(\mathrm{n}=$ 26) with $76.5 \%$ of colostomies. Table 2 shows the different digestive segments of the stoma.

Of the stomas performed, $67.65 \%(\mathrm{n}=23)$ were temporary and $32.35 \%(\mathrm{n}=$ 11) were permanent. $50 \%$ of the stomas were terminal. The complication rate was $67.6 \%$. Stomal oedema was the most common early complication with $38.2 \%$ of cases. Peristomal dermatitis accounted for $50 \%$ of late complications. Table 3 shows all the complications found.

All patients used colostomy bags and the majority $(\mathrm{n}=18), 52.9 \%$, had a 
Table 1. Socio-demographic characteristics of patients.

\begin{tabular}{|c|c|c|c|}
\hline \multicolumn{2}{|c|}{ Item } & $\mathrm{N}$ & $\%$ \\
\hline \multirow{2}{*}{ Gender } & Male & 22 & 22.65 \\
\hline & Female & 12 & 12.35 \\
\hline \multirow{6}{*}{ Age range } & $15-25$ & 3 & 8.8 \\
\hline & $26-35$ & 6 & 17.6 \\
\hline & $36-45$ & 12 & 35.4 \\
\hline & $46-55$ & 7 & 20.6 \\
\hline & $56-65$ & 2 & 5.8 \\
\hline & $>65$ & 4 & 11.8 \\
\hline \multirow{5}{*}{ Profession } & Civil servant & 9 & 26.47 \\
\hline & Shopkeeper & 12 & 35.29 \\
\hline & Housewife & 4 & 11.76 \\
\hline & Pupil/student & 5 & 14.70 \\
\hline & Unemployed & 4 & 11.76 \\
\hline \multirow{3}{*}{ Education level } & Primary & 2 & 5.9 \\
\hline & Secondary & 18 & 52.9 \\
\hline & Higher & 14 & 41.2 \\
\hline \multirow{4}{*}{ Marital status } & Single & 9 & 26.5 \\
\hline & Married/couple & 23 & 67.64 \\
\hline & Divorced & 1 & 2.94 \\
\hline & Widowed & 1 & 2.94 \\
\hline
\end{tabular}

Table 2. Distribution of organs attached to the skin.

\begin{tabular}{ccccc}
\hline & Item & & $\mathrm{N}$ & $\%$ \\
\hline \multirow{2}{*}{ Bypass stoma } & & Colostomy & 26 & 76.5 \\
& & Ileostomy & 5 & 14.7 \\
\multirow{2}{*}{ Feeding stoma } & & Gastrostomy & 1 & 2.9 \\
& & Jejunostomy & 2 & 5.9 \\
& Total & & 34 & 100 \\
\hline
\end{tabular}

pouch change frequency of between 3 and 6 days. $23.5 \%$ of patients $(n=8)$ had pouch change frequency of less than 3 days and also $23.5 \%(n=8)$ had a pouch change frequency of more than 6 days.

The majority of patients (79.41\%) had not regained normal sexual activity. Partner discomfort was the most frequent reason, with $76.5 \%$ of cases resulting in separation of the couple in $35.3 \%$ of cases. The average time to return to sexual activity was 8 months for men and 9 months for women.

Quality of life was severely impaired (QOL between 0 and 40 ) in $9.1 \%$ of 
Table 3. Ostomy complications.

\begin{tabular}{cccc}
\hline & Complications & $\mathrm{N}$ & $\%$ \\
\hline \multirow{3}{*}{$\begin{array}{c}\text { Early } \\
\text { complications }\end{array}$} & Stomal haemorrhage & 11 & 32.4 \\
& Stomal oedema & 13 & 38.2 \\
& Desinsertion & 1 & 2.9 \\
& Evisceration & 6 & 17.6 \\
Retraction & 2 & 5.9 \\
Late & Peristomal abcess & 7 & 20.6 \\
\hline Peristomal fistula & 3 & 8.8 \\
& Stenosis & 2 & 5.9 \\
& Dermatittis & 1 & 2.9 \\
& Eventration & 17 & 50 \\
& Stomal prolapse & 2 & 5.9 \\
& Denutrition & 5 & 14.5 \\
& Hydroelectrical disorders & 5 & 29.4 \\
\hline
\end{tabular}

patients with a permanent stoma and $17.4 \%$ of patients with a temporary stoma. Women had a worse quality of life than men. The QOL score was between 0 and 40 in $16.7 \%$ of women and $13.6 \%$ of men. None of our patients had a normal quality of life. Table 4 shows the Stoma Quality of Life (QOL) score according to the type of stoma and the gender of the patients.

According to the Body Image Scale, Self-image was very dissatisfied (score between 0 and 14) in $36.4 \%$ of the patients with a permanent ostomy and in $8.7 \%$ of the patients with a temporary ostomy. Self-image was normal in $25 \%$ of the women and in none of the men. Table 5 shows the BIS self-image according to the type of stoma and gender.

\section{Discussion}

During our study, we collected 34 patients who underwent surgery leading to the creation of a stoma, 22 of whom were men, with a sex ratio of 1.8 in favor of men, which was also found by Traore [5], and B. Ameur [7] in Africa, and Yin in Asia [3]. Adults around the fourth decade were the most affected, as in many African studies [5] [12], unlike Western studies which found a peak around the sixth decade. This difference could be explained by the fact that the colorectal cancer pathology that is most often responsible for colostomy is the preserve of the young adult in our context [13].

Temporary colostomy was the most common procedure, as in the literature [3] [5], and the segment most frequently removed was the sigmoid, as was the case for all the authors, due to its easier mobilisation [7] [8] [14].

The postoperative complication rate was $67.6 \%$, which is high compared to 
Table 4. Quality of life of patients according to type of stoma and gender.

\begin{tabular}{cccc}
\hline & $\begin{array}{c}\text { Very impaired } \\
\text { QOL } 0-40 \\
\mathrm{~N}(\%)\end{array}$ & $\begin{array}{c}\text { Moderately } \\
\text { impaired QOL } \\
41-80 \mathrm{~N}(\%)\end{array}$ & $\begin{array}{c}\text { Normal QOL } \\
81-100 \mathrm{~N}(\%)\end{array}$ \\
\hline $\begin{array}{c}\text { Permanent stoma } \\
(\mathrm{n}=11)\end{array}$ & $1(9.1)$ & $10(90.9)$ & 0 \\
$\begin{array}{c}\text { Temporary stoma } \\
(\mathrm{n}=23)\end{array}$ & $4(17.4)$ & $19(82.6)$ & 0 \\
Female $(\mathrm{n}=12)$ & $2(16.7)$ & $10(83.3)$ & 0 \\
Male $(\mathrm{n}=22)$ & $3(13.6)$ & $19(86.4)$ & 0 \\
\hline
\end{tabular}

Table 5. BIS score according to the type of stoma and the gender of the patients.

\begin{tabular}{cccc}
\hline & $\begin{array}{c}\text { Very } \\
\text { dissatisfied } \\
0-14 \mathrm{~N}(\%)\end{array}$ & $\begin{array}{c}\text { Moderately } \\
\text { dissatisfied } \\
15-29 \mathrm{~N}(\%)\end{array}$ & $\begin{array}{c}\text { Normal } \\
30-40 \mathrm{~N}(\%)\end{array}$ \\
\hline Permanent stoma $(\mathrm{n}=11)$ & $4(36.4)$ & $6(54.5)$ & $1(9.1)$ \\
Temporary stoma $(\mathrm{n}=23)$ & $2(8.7)$ & $19(82.6)$ & $2(8.7)$ \\
Female $(\mathrm{n}=11)$ & 0 & $9(75)$ & $3(25)$ \\
Male $(\mathrm{n}=22)$ & $6(27.3)$ & $16(72.7)$ & 0 \\
\hline
\end{tabular}

the studies by Yin, who found $36.4 \%$ [3], and a Tunisian study which found a complication rate of $57 \%$ [7]. This difference could be linked to the early diagnosis, optimal management with more adequate technical facilities in these countries. The most common complication is peristomal dermatitis at $50 \%$. This irritation is very present for ileostomies with the rejection of proteolytic enzymes on the skin. It is also the leading cause in China [3] and Denmark [6] because ostomy care is not mastered by ostomates themselves and the abusive use of plasters to hold the pouch in place by ostomates maintains the permanent irritation of the peri-stomal area.

Sexuality is an essential element for the well-being of ostomates, as it interacts with body image and self-fulfillment.

The majority of our patients had not resumed sexual activity before 8 months, not because of an organic defect but mainly because of the partner's embarrassment. This resumption is even later in women than in men. These same observations were made by Persson [15] and Salter [16] who found a decrease in sexual desire after the stoma. Contrary to Van De Wiel who found that ostomy surgery had very little influence on sexual motivation [17].

Quality of life is an important monitoring element for the future of ostomy patients as they must learn to be independent. This monitoring takes into account physical, psychosocial and social well-being and it is widely recognized that the measurement of such parameters is difficult [18], certainly due to the subjectivity of the answers. The quality of life in our study was unsatisfactory for all of our patients, in contrast to the work of Thomas [12] and Kraise [19] who 
found some patients with a normal quality of life, respectively $78 \%$ and $68 \%$ of their study population.

In the decision tree that led to the creation of the stoma, most of our patients thought they had not been sufficiently informed about the surgery and the results [12].

Permanent ostomates have a better quality of life than temporary ostomates similar to Beaubrun et al. in 2018 [4]. The fact that an ostomy is temporary would give the patient the hope of regaining normal elimination and paradoxically would flourish the process of adaptation and autonomy [4]. The quality of life would be favored by good physical self-esteem in patients with a temporary stoma, and good emotional self-esteem associated with a preserved body image in patients with a permanent stoma. The latter had higher self-esteem than the temporary ostomy patients.

\section{Limitations of the Study}

Our study was limited by its monocentric nature and relatively short follow-up time. A multicentric study with larger sample size and longer follow-up would allow a better assessment of the quality of life of these patients and to see if it improves over time, especially for patients with a permanent stoma.

\section{Conclusion}

Our aim was to determine the impact of digestive stomas on the quality of life of patients. At the end of this study, young adult males between the 3rd and 4th decade are the most affected. Tumor pathology is the main indication leading to the creation of an ostomy, whether it is for feeding or exoneration. The quality of life of our ostomates remains average, although it is clearly higher in the definitive ostomates than in the temporary ostomates who are permanently stressed by the date of recovery.

\section{Authors' Contributions}

GBM and GAB: Study design.

RLKDS: Data collection.

JCCN and RLKDS: Data analysis.

GBM, JCCN: Drafting the manuscript.

GAB, YBEM: Proofreading and editing the manuscript.

BNN: Final revision of the manuscript.

MAS: Final Approval for submission.

\section{Conflicts of Interest}

The authors declare no conflict of interest.

\section{References}

[1] Soravia, C., Beyeler, S. and Lataillade, L. (2005) Les stomies digestives: Indications, 
complications, prise en charge pré et post opératoire. Revue Médicale Suisse, 1, 708-709, 711-714, 717-718.

[2] Prudhomme, M. (2014) Complications stomiales après amputation abdominopérinéale. http://chirurgie-digestive-sat.aphp.fr/publications-du-service/journees-de-chirurgie -digestive-de-saint-antoine/45emes-journees-de-chirugie-digestive/complications-st omiales-apres-amputation-abdomino-perineale/

[3] Yin, T.-C., Tsai, H.-L., Yang, P.-F., Su, W.-C., Ma, C.-J., Huang, C.-W., et al. (2017) Early Closure of Defunctioning Stoma Increases Complications Related to Stoma Closure after concurrent Chemoradiotherapy and Low Anterior Resection in $\mathrm{Pa}$ tients with Rectal Cancer. World Journal of Surgical Oncology, 15, Article No. 80. https://wjso.biomedcentral.com/articles/10.1186/s12957-017-1149-9 https://doi.org/10.1186/s12957-017-1149-9

[4] Beaubrun Diant, L., Sordes, F. and Chaubard, T. (2018) Impact psychologique de la stomiesur la qualité de vie des patients atteints d'un cancer colorectal: Rôle de l'image du corps, l'estime de soi et l'anxiété. Bulletin du Cancer, 105, 573-580. https://doi.org/10.1016/j.bulcan.2018.03.005

[5] Traore, A., Diakite, I., Togo, A., Dembele, B.T., et al. (2010) Stomiesdigestives en chirurgie générale du CHU Gabriel Toure. Mali Medical, 25, 52-56.

[6] Nybaek, H. and Jemec, G. (2010) Skin Problems in Stoma Patients. Journal of the European Academy of Dermatology and Venereology, 24, 249-257. https://doi.org/10.1111/j.1468-3083.2010.03566.x

[7] Ameur, H.B., Affes, N., Rejab, H., Abid, B., Boujelbene, S., Mzali, R., et al. (2014) Les complications chirurgicales des colostomies. La Tunisie Medicale, 92, 482-487.

[8] Takongmo, S., Ndi Ombgba, R., Masso Mise, P., Pisoh, T., Nzokou, A. and Sosso, M.A. (2013) Les entérostomies au CHU de Yaoundé: Indications et résultat à propos d'une série de 42 patients. Health Science and Diseases, 10.

[9] Lai, E., Peterson, A.C., Liu, G.P., et al. (2018) Psycometric Validation of the Stoma QOL in a Canadian Cross-Sectional Sample of Colostomy and Ileostomy Patients. Scandinavian Journal of Gastroenterology, 53, 721-726. https://doi.org/10.1080/00365521.2018.1457713

[10] Elfeki, H., Thyø, A., Nepogodiev, D., Pinkney, T.D., White, M., Laurberg, S., et al. (2018) Patient and Healthcare Professional Perceptions of Colostomy-Related Problems and Their Impact on Quality of Life Following Rectal Cancer Surgery. BJS Open, 2, 336-344. https://doi.org/10.1002/bjs5.69

[11] Vonk-Klaassen, S.M., de Vocht, H.M., den Ouden, M.E.M., Eddes, E.H. and Schuurmans, M.J. (2016) Ostomy-Related Problems and Their Impact on Quality of Life of Colorectal Cancer Ostomates: A Systematic Review. Quality of Life Research, 25, 125-133. https://doi.org/10.1007/s11136-015-1050-3

[12] Kiliç, E., Taycan, O., Bell, A.K. and Özmen, M. (2007) The Effect of Permanent Ostomy on Body Image, Self-Esteem, Marital Adjustment, and Sexual Functioning. Turkish Journal of Psychiatry, 18, 302-310.

[13] Takongmo, S., Essame-Oyono, J.L., Binam, F., Sadou and Malonga, E. (2000) Les cancers colo-rectaux du sujet de moins de 40 ans a Yaoundé: Des particularités anatomo-cliniques? Medecine d'Afrique Noir, 47, 101-104.

[14] Shabbir, J. and Brritton, D.C. (2010) Stoma Complications: A Literature Overview. Colorectal Disease, 12, 958-964. https://doi.org/10.1111/j.1463-1318.2009.02006.x

[15] Persson, E. and Hellstrom, A.L. (2002) Experiences of Swedish Men and Women 6 to 12 Weeks after Ostomy Surgery. Journal of Wound, Ostomy and Continence Nursing, 26, 298-305. https://doi.org/10.1097/00152192-200203000-00011 
[16] Salter, M. (1992) What Are the Differences in Body Image between Patients with a Conventional Stoma Compared with Those Who Have Had a Conventional Stoma Followed by a Continent Pouch? Journal of Advanced Nursing, 17, 841-848. https://doi.org/10.1111/j.1365-2648.1992.tb02006.x

[17] van De Wiel, H.B.M., Weijmar Schultz, W.C.M., Hengeveld, M.W. and Staneke, A. (1991) Sexual Functioning after Ostomy Surgery. Sexual and Marital Therapy, 6, 195-207. https://doi.org/10.1080/02674659108406534

[18] Ayaz-Alkaya, S. (2019) Overview of Psychosocial Problems in Individuals with Stoma: A Review of Literature. International Wound Journal, 16, 243-249. https://doi.org/10.1111/iwj.13018

[19] Krouse, R., Grant, M., Ferrell, B., Dean, G., Nelson, R. and Chu, D. (2007) Quality of Life Outcomes in 599 Cancer and Non-Cancer Patients with Colostomies. Journal of Surgical Research, 138, 79-87. https://doi.org/10.1016/j.jss.2006.04.033 